\title{
Teething troubles for UK technology labs
}

\section{London}

A THREE-YEAR-OLD experiment in government-industry research cooperation in Britain - set up in parallel to similar US efforts - has run into trouble and appears to be heading for a shake-up. The first two of the programme's 12 Interdisciplinary Research Centres (IRCs) have received critical reviews by independent experts, and, in a climate of funding cutbacks, at least one of them could eventually be closed, sources say.

The poor performance of the first centres to be reviewed is an inauspicious beginning for the ambitious UK effort, and a worrying harbinger of things to come. Intended as Britain's answer to a recent series of US government-industry laboratories (the Science and Technology Centers and Engineering Research Centers of the National Science Foundation), the IRCs are remarkably similar to their US counterparts. Both countries give their centres four-year rolling grants (averaging about $£ 2$ million annually for each of the UK centres) and expected them to match the government funding with support from industrial and academic co-sponsors, largely to encourage transfer of technology between the sectors.

But the UK programme had the misfortune of coming just as the British economy was about to hit a downturn and the budget of its sponsor, the Science and Engineering Research Council (SERC), was facing a $£ 40$ million shortfall. Economics alone cannot, however, explain the problems of the University of Cambridge's centre for superconductivity and the centre on engineering design run by a consortium headed by the University of Glasgow, the two centres now under SERC review. As the independent researchers who examined the two centres earlier this year discovered, both have been plagued with management and organizational troubles that severely limited their research productivity in the first year.

SERC has decided to put any new centres in abeyance while it ponders what to do with its $£ 20$ million programme. "We just want to sit and think a little," says David Clark, deputy director of SERC, who runs the IRC programme. "It's an appropriate time to pause, because we're short of money." Funding shortages have forced SERC to ask the centres to cut spending by 10 per cent this year, and 5 per cent next year.

Reviewing the history of the centres has proved useful, if sobering, for SERC. Indeed, the story of at least the two IRCs under review might be a case study in exactly how not to set up an innovative new research centre. By its own admission, SERC violated several of the unwritten rules of big science manage- ment in setting up its IRCs, and the agency is revamping the programme to avoid such mistakes in the future.

As opposed to many of the first 12 centres, future IRCs (if there are any) will:

\section{Respond to an established demand.}

Having a group of researchers in place and eager for a centre makes it far more likely that the centre will succeed once in place. Rumour has it that SERC set up a superconductivity IRC mainly to please then-Prime Minister Margaret Thatcher, who had seen a news article about superconductivity and called a science official to find out what Britain was doing in the area. Similarly, the idea for the engineering design centre was SERC's alone; with little established base to build on at Glasgow, it took the centre nine months just to assemble staff and find laboratory space in a nearby research park before it could do its first science. "We didn't even have room to sit, much less a place to start research in earnest," says Bernerd Capaldi, who directs the 30 -person Glasgow centre.

"When we set up the first centres, we did it from the 'top down', with the initiative coming from us," adds Clark. "In the future we'll do it 'bottom up', based on proposals that the community brings forward."

Start with strong leadership. The first two centres to be critically reviewed

\section{The perils of industrial participation}

\section{Cambridge}

As mantras go, 'industrial participation' has little competition in the world of government and academic research centres. Without a healthy dose of industry support and collaboration, current thinking goes, basic research will not become technology and technology will not become products. And that, in a time when society is increasingly asking science to prove its worth, is unthinkable. But as one UK research centre found out, industrial participation can sometimes be more trouble than it is worth.

When the UK Science and Engineering Research Council (SERC) set up an Interdisciplinary Research Centre for superconductivity at the University of Cambridge in 1988, the centre was encouraged to find at least 50 per cent of its support from industry by the end of its first six years. To help it along, SERC found it a director who not only came from industry, but would also bring some expensive equipment with him. Peter Duncan had been research director for Tube Investment Ltd, a UK technology company. When it went out of the research business, he and the surplus Tube Investment electron microprobe analyser moved to Cambridge.

Things would never again look so good. Duncan soon left, and the microprobe analyser he brought with him turned out to be 15 years old and every bit as unreliable as a machine of that age might predictably be. How useful is it? "It serves us in a limited way," says current director Yao Liang, after some pause.

Liang, a well-respected Cambridge solid-state physicist, replaced Duncan in 1989. But the equipment problems were just beginning.

The UK company GEC offered the centre what appeared to be a real prize - a molecular beam epitaxy (MBE) machine, worth more than $£ 300,000$, that the company was no longer using.

MBEs can create films one atomic layer at a time, and are invaluable for creating new superconducting circuits. But there was one small catch: the machine had been contaminated with cadmium and mercury and would require cleaning. It took a postdoctoral researcher 18 months of scrubbing with steel wool before the MBE was free of the toxic chemicals. Total cost to the centre: hard to estimate, but at industrial rates at least $£ 100,000$.
Even new equipment found ways to complicate the infancy of the centre. When Cambridge decided to buy a $£ 100,000$ SQUID (superconducting quantum interference device) magnetometer to measure tiny magnetic fields, it had a choice of proven machines from US companies, or a half-working prototype from a Cambridge company called Cryogenic Consultants. Officials at the centre decided that it would be politic to buy British, so Cambridge selected the UK company, to its subsequent regret. Cryogenic Consultants delivered the magnetometer two years late and laboratory staff are still trying to get the machine to work properly. "It was competitive on paper," is the best Liang can say about it.

At its two-year mark, the Cambridge centre claims about a 30 per cent industrial share in its $£ 6$ million a year support. But about half of that, says Liang, is "in kind" - equipment, goods and non-monetary contributions; the stuff of headaches, if experience so far is any guide. Perhaps the best rule for future industrial participation might be one of the oldest: cash only, please. 